\title{
Do Dermis-Derived Stem Cells Have the Same Characteristics as Bone Marrow- and Adipose Tissue-Derived Stem Cells?
}

\author{
M. Bohac, S. Polak, J. Fedels, Z. Varchulova Novakova, J. Rusnakova, and L. Danisovic
}

\begin{abstract}
In this study we performed comprehensive biological and morphological analysis of dermis-derived stem cells and compared them with bone marrow- and adipose tissue-derived stem cells. According to obtained results we can emphasize that analyzed somatic stem cells shared morphological features, expression of surface antigens as well as growth kinetics, but differ in chondrogenic potential. Skin-derived stem cells have an inferior potential for chondrogenic differentiation. So this fact decreases their potential for cartilage tissue engineering.
\end{abstract}

Index Terms-Biological characteristics, chondrogenic differentiation, morphology, somatic stem cells.

\section{INTRODUCTION}

Damaged or lost articular cartilage as a consequence of inborn anomaly, pathological process or trauma leads to progressive debilitation, which has major impact on the life quality of the affected individuals in all age groups. It is difficult to treat these patients, because mature articular cartilage has a limited self-repairing potential [1]. Small defects are regenerated by migration of chondrocytes, while full-thickness damages are healed by formation of inferior fibrocartilage [2]. However, in many cases osteoarthritis is developed and surgical intervention is often the only option. Unfortunately, current treatment techniques for cartilage reparation are insufficient and it is not possible to obtain expected results.

Recently, somatic stem cells / mesenchymal stem cells MSCs represent big hope in this respect. Stem cells are found in all tissues of higher multicellular organisms during all stages of ontogenesis. They are primitive undifferentiated cells with the unique ability of long term self-renewing. Another important feature of MSCs is their plasticity - the potential for terminal differentiation into other cell types. Therefore, they play an important role in the embryonic

Manuscript received May 10, 2013; revised July 16, 2013. This work was supported by grant VEGA No. 1/0706/11 and by grant of Ministry of Health of the Slovak Republic No. 2007/36-UK-07.

M. Bohac, and J. Fedeles are with the Department of Plastic, Reconstructive and Aesthetic Surgery, Faculty of Medicine, Comenius University, Pažítkova 4, 82101 Bratislava, Slovakia (e-mail: bohac.md@gmail.com).

S. Polak, and J. Rusnakova are with the Institute of Histology and Embryology, Faculty of Medicine, Comenius University, Sasinkova 4, 81108 Bratislava, Slovakia (e-mail: stefan.polak@fmed.uniba.sk).

Z. Varchulova Novakova and L. Danisovic are with the Institute of Medical Biology, Genetics and Clinical Genetics, Faculty of Medicine, Comenius University, Sasinkova 4, 81108 Bratislava, Slovakia (e-mail: lubos.danisovic@fmed.uniba.sk). development, replacing worn out cells and regeneration of damaged tissues [3].

MSCs are adherent and have a fibroblast-like morphology. They are also able to produce colony forming units-fibroblast (CFU-F) when cultured in vitro. They are positive for a variety of surface markers, including CD29, CD44, CD56, CD73, CD90, CD105, CD166, CD271, STRO-1 and Sca-1. On the contrary, they are negative for CD31, CD34, CD45 and HLA-DR [4]. More recently, it was shown that MSCs express markers which are typical for embryonic stem cells, including OCT4, Nanog and Sox2. These findings provide clarification of their undifferentiated state [5].

Bone marrow was the first source of MSCs but in respect to clinical application it has several disadvantages, including invasive and painful sampling procedure and the decline in MSCs number and differentiation potential with increasing age of donor [6]. For that reason, alternative sources of MSCs are subject to intensive investigation. In that context, attention turns to adipose tissue which is abundant in human body and represents reliable and relatively safe source of MSCs (one gram of adipose tissue contains approximately $1 \cdot 10^{6}$ MSCs) [7]. More recently, it was shown that dermis seem to be another promising source, which contains MSCs. These cells are easy to obtain and they should be expanded to high quantities. Moreover, they have potential to differentiate into both neural and mesodermal cell types [8].

The objective of this study was to perform comprehensive biological and morphological analysis of dermis-derived stem cells and compared them with bone marrow- and adipose tissue-derived stem cells in respect to cartilage regeneration.

\section{EXPERIMENTAL}

\section{A. Isolation and Cell Culture}

All sampling procedures were performed in accordance with The Helsinki Declaration; always following patient's informed consent.

Bone marrow-derived stem cells (BMSCs) were isolated from fresh bone marrow, supplemented with heparin. To separate stem cells, gradient centrifugation using Ficol-Paque at $1800 \mathrm{rpm}$ for $30 \mathrm{~min}$ was used. Cells were washed twice with phosphate buffered saline (PBS; Oxoid, GB) and centrifuged at $1200 \mathrm{rpm}$ for $5 \mathrm{~min}$. Pellets were resuspended in $\alpha$-MEM (PAA, Austria) with $10 \%$ fetal bovine serum (FBS; PAA, Austria), $100 \mathrm{U} / \mathrm{ml}$ Penicillin and $100 \mu \mathrm{g} / \mathrm{ml}$ Streptomycin (PAA, Austria). Cells were plated in $100 \mathrm{~mm}$ Petri dishes and cultured at $37^{\circ} \mathrm{C}$ in a humidified 
atmosphere of $5 \% \mathrm{CO}_{2}$. After $24 \mathrm{~h}$ non-adherent cells were removed by changing the culture medium.

Adipose tissue-derived stem cells (ATSCs) were obtained from fresh subcutaneous fat, which was rinsed with PBS and disaggregated with scalpel. Obtained specimens were digested by $0,1 \%$ collagenase type I (PAA, Austria) for 1 hour at $37^{\circ} \mathrm{C}$, then dissociated by gentleMACS and centrifuged at $1200 \mathrm{rpm}$ for $5 \mathrm{~min}$. The supernatant was aspirated. The pellet was resuspended in PBS following centrifugation. The final pellet was resuspended in D-MEM (PAA, Austria) with $10 \%$ FBS, $100 \mathrm{U} / \mathrm{ml}$ Penicillin and 100 $\mu \mathrm{g} / \mathrm{ml}$ Streptomycin. Cells were seeded on $100 \mathrm{~mm}$ Petri dishes and were incubated in a humidified atmosphere of 5\% $\mathrm{CO}_{2}$ at $37^{\circ} \mathrm{C}$. Non-adherent cells were aspirated after $48 \mathrm{~h}$ and fresh medium was added.

Dermis-derived stem cells (DSCs) were obtained from dermis, which was minced into small pieces and carefully rinsed with PBS, then digested by $0.25 \%$ trypsin for $2 \mathrm{~h}$ at $37^{\circ} \mathrm{C}$, then dissociated by gentleMACS and centrifuged at $1200 \mathrm{rpm}$ for $5 \mathrm{~min}$. Obtained pellet was resuspended in $\alpha$-MEM with $20 \%$ fetal bovine serum, $100 \mathrm{U} / \mathrm{ml}$ Penicillin and $100 \mu \mathrm{g} / \mathrm{ml}$ Streptomycin. Cells were plated in $100 \mathrm{~mm}$ Petri dishes and cultured at $37^{\circ} \mathrm{C}$ in a humidified atmosphere of $5 \% \mathrm{CO}_{2}$. After $24 \mathrm{~h}$ non-adherent cells were removed by changing the culture medium.

During subsequent cultivation, the medium was refreshed every three days. When the cells reached they were detached by trypsin and sub-cultured up to the third passage.

\section{B. Growth Kinetics}

The evaluation of the growth characteristics of BMSCs, ATSCs and DSCs was performed by generating a growth curve prepared according to a standard method. Briefly, suspension of selected cells $\left(5 \cdot 10^{4}\right.$ cells $\left./ \mathrm{ml}\right)$ at passage 3 was seeded into $60 \mathrm{~mm}$ Petri dishes. During the next 7 days of cultivation, three dishes were monitored on a daily basis for density. Growth curves were plotted by Microsoft Office Excel 2003 (Miscrosoft, USA).

\section{Phenotypic Characterization}

Stem cells from the third passage were detached by $0.25 \%$ trypsin digestion and then resuspended in blocking buffer consisting of PBS with $0.5 \%$ bovine serum albumin (PAA, Austria). Cell suspensions of $2.5 \cdot 10^{5}$ cells per sample were incubated $30 \mathrm{~min}$ at $4{ }^{\circ} \mathrm{C}$ with the respective antibody (against human CD14, CD29, CD34, CD44, CD45, CD73, CD90, CD105, CD166 and HLA-DR). The cells were then washed by PBS and incubated with conjugated-FITC antibodies for $30 \mathrm{~min}$ at $4^{\circ} \mathrm{C}$. Prior to analysis they were washed and resuspended by PBS. In each case, 10000 events were acquired and analyzed by BD FACSAria flow cytometer using BD FACSDiva software (BD, USA).

\section{TEM Analysis}

Cells appointed for transmission electron microscopy (TEM) were fixed in $2.5 \%$ glutaraldehyde (Sigma Aldrich, Germany), $\mathrm{pH} 7.2$, at $4^{\circ} \mathrm{C}$ for four hours. After fixation, cells were carefully rinsed by PBS and post-fixed with $2 \%$ osmium tetraoxide (Serva, Germany) for 2 hours, then rinsed in distilled water and dehydrated in a graduated series of ethanol. (Centralchem, Slovakia). Subsequently, the samples were embedded in Durcupan (Fluka, USA) and cut into semi-thin sections. The obtained sections were stained by toluidine blue (Sigma Aldrich, Germany) for 10 minutes, and cut into ultra-thin sections. Then, they were mounted on 200 mesh copper grids, double stained using uranyl acetate and lead citrate (Serva, Germany) and examined using a TEM Philips CM 100 (Philips, Holland).

\section{E. Chondrogenic Differentiation}

For chondrogenic differentiation, a three-dimensional pellet culture system was used. Pellets were formed by centrifugation of $1 \cdot 10^{6}$ stem cells from the third passage at $1500 \mathrm{rpm}$ for $10 \mathrm{~min}$ in $15 \mathrm{ml}$ polypropylene tubes. The chondrogenic medium consisted of D-MEM, 10\% FBS, 100 $\mathrm{U} / \mathrm{ml}$ Penicillin, $100 \mu \mathrm{g} / \mathrm{ml}$ Streptomycin and $10 \mathrm{ng} / \mathrm{ml}$ TGF- $\beta 1$ (Millipore, USA). All tubes were maintained in the incubator at $37^{\circ} \mathrm{C}$ with humidified atmosphere of $5 \% \mathrm{CO}_{2}$. The culture medium was carefully refreshed every third day during 21 days. After 21 days, experiment was terminated and the analysis of collagen type I and collagen type II expression was performed by real time PCR according standard protocol. Briefly, total RNA was isolated with GeneJET RNA Purification Kit (Fermentas, USA) according to the manufacturer's protocols. First-strand cDNA was synthesized of total RNA with Maxima First Strand cDNA Synthesis Kit for RT-qPCR (Fermentas, USA). Real-time reverse transcription-polymerase chain reaction (RT-PCR) was performed using Eco Real-Time PCR System (Illumina, USA). Primers sequences used were as follows: Collagen I Forward:CCAGAAGAACTGGTACATCAGCAA, Reverse: CGCCATACTCGAACTGGAATC and Collagen II Forward: GAAACCATCAATGGTGGCTTCC, Reverse: CGATAACAGTCTTGCCCCACTT. Human glyceraldehyde-3-phosphate dehydrogenase (GAPDH) and beta-actin were used as internal controls. Reactions were carried out under the following conditions: $95^{\circ} \mathrm{C}$ for 2 minutes, followed by 40 cycles $95^{\circ} \mathrm{C} 15$ seconds and $60^{\circ} \mathrm{C}$ for 1 minutes.

\section{RESULTS}

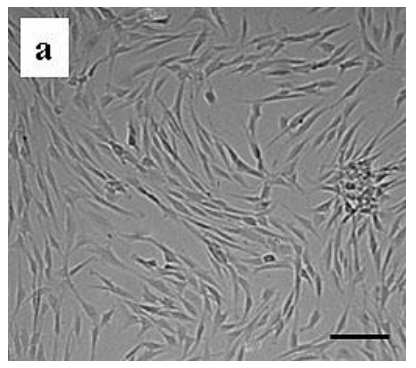

Fig. 1 a. Morphology of cultured BMSCs $($ scale bar $=100 \mu \mathrm{m}$ ).

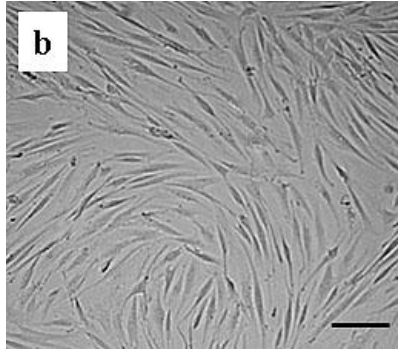

Fig. 1 b. Morphology of cultured ATSCs (scale bar $=100 \mu \mathrm{m}$ ) 


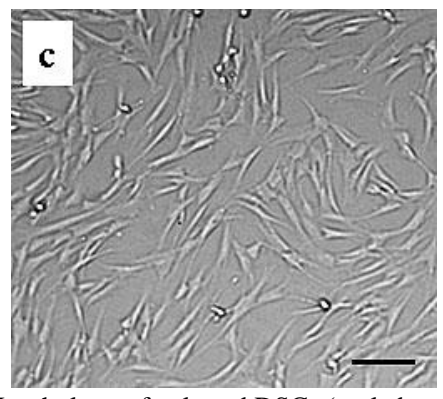

Fig. 1 c. Morphology of cultured DSCs $($ scale bar $=100 \mu \mathrm{m})$.

BMSCs, ATSCs and DSCs were attached on the Petri dishes after $24 \mathrm{~h}$ and started to proliferate in colonies. They had fibroblast-like morphology. After $7-10$ days they reached $80 \%$ confluency and were sub-cultured. In the next three passages they displayed typical fibroblastoid morphology (Fig. 1).

Fig. 2 shows course of BMSCs, ATSCs and DSCs proliferation. Stem cells showed similar kinetics of proliferation; they have short lag phase, a log phase at exponential rate from 3 to 6 days, and a plateau phase.

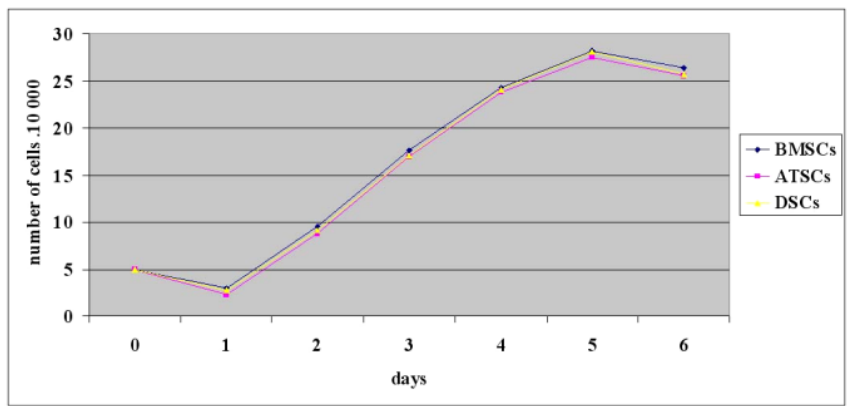

Fig. 2. Growth curves of BMSCs, ATSCs and DSCs.

Fig. 3 shows the results obtained from phenotypic characterization. Analysed stem cells shared the expression of CD29, CD44, CD73, CD90, CD105 and CD166. They were negative for CD14, CD34, CD45 and HLA-DR.

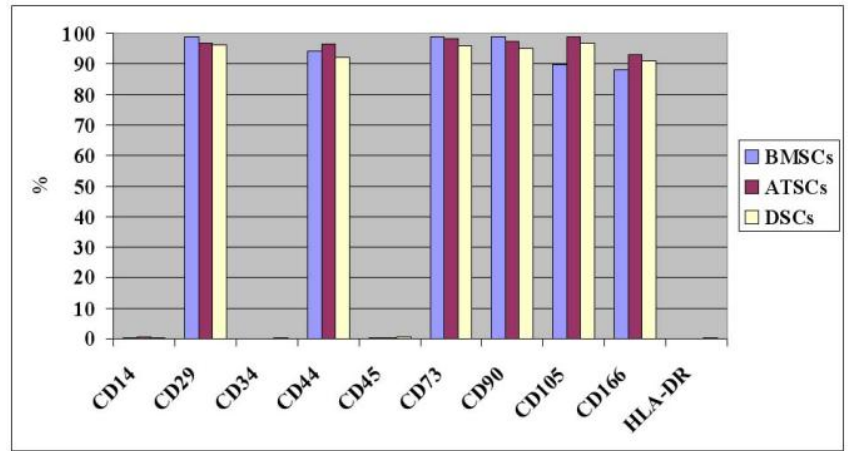

Fig. 3. Immunophenotypic characterization of BMSCs, ATSCs and DSCs.

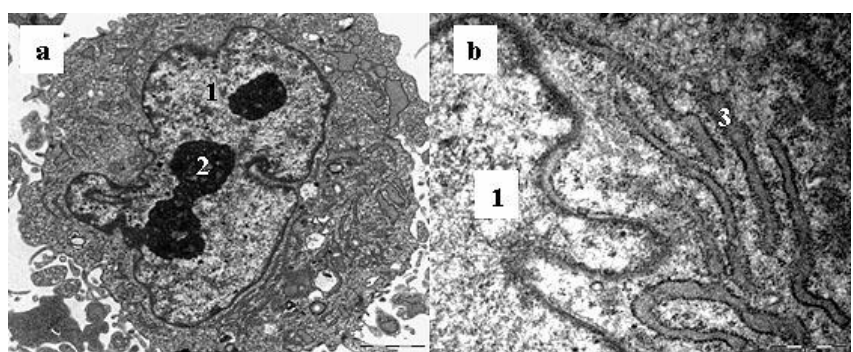

Fig. 4. TEM analysis of BMSCs (1=nucleus, $2=$ nucleolus, $3=$ endoplasmatic reticulum).
TEM analysis showed similar morphology of all analysed stem cells (Fig. 4-Fig. 6). They have normal ultrastructure of the protheosynthetically active cells. They have irregular shape with noticeable nuclei with a large amount of euchromatine. Every nucleus contained several nucleoli. Cisterns of rough endoplasmic reticulum were present in their cytoplasm.

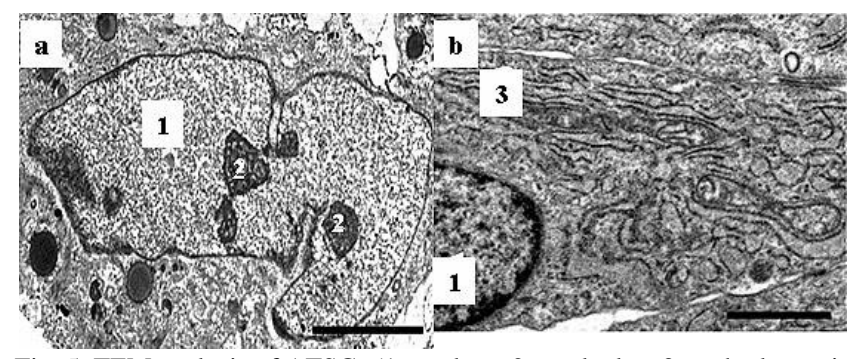

Fig. 5. TEM analysis of ATSCs (1=nucleus, $2=$ nucleolus, $3=$ endoplasmatic reticulum).

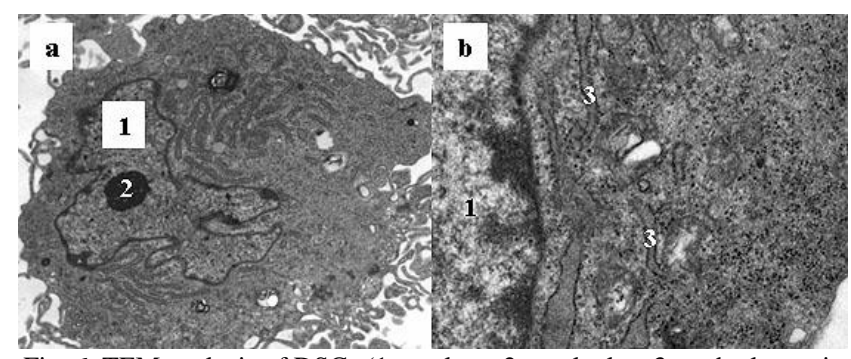

Fig. 6. TEM analysis of DSCs ( $1=$ nucleus, $2=$ nucleolus, $3=$ endoplasmatic reticulum).

Analysis of expression of selected genes showed that DSCs have decreased potential in production of chondrogenic marker (collagen type II) while expression of collagen type I was increased when compared with BMSCs and ATSCs (Fig. 7).

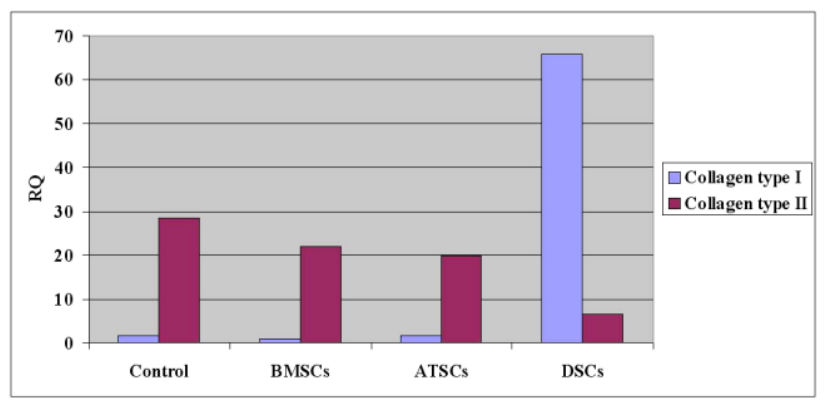

Fig. 7. Relative expression of collagen type I and collagen type II (chondrocytes from first passage were used as positive control).

\section{DISCUSSION}

Recently, tissue engineering and regenerative medicine belong to quickly emerging biomedical fields. They use various types of cells with/without biomaterials to produce artificial tissues for potential application in human medicine [9]. The stem cells have great potential in above context. In the present work, MSCs from three sources, including bone marrow, adipose tissue and dermis were isolated and expanded under in vitro conditions. The comprehensive analysis and comparison of their biological and morphological properties was performed. Moreover, the chondrogenic potential was assessed in respect to cartilage 
engineering.

Our findings showed that, BMSCs, ATSCs and DSCs should be relatively easily harvested and expanded in vitro. Isolated cells adhered immediately after seeding and started to form colonies. During following days of cultivation they proliferate rapidly. They have fibroblastoid morphology. On the ultrastructural level, they display normal morphology of the protheosynthetically active cells. Similar observations from experiments with somatic stem cells originated from various tissues were recorded by our group and other authors, not only in human but also in other species [7], [8], [10]-[12].

Pioneer studies focusing on isolation and characterization of stem cells were based mainly on their ability to adhere on substrate and to produce CFU-F [13]. At present, this approach is not sufficient, and therefore the flow cytometric analyses are used to define the stem cells more precisely according to expression of specific surface markers. Despite the fact that MSCs represent heterogeneous population of cells, the minimal criteria were established by International society for cytotherapy. According to them, MSCs have to be multipotent and positive at least for CD73, CD90 and CD105 and negative for marker typical for hematopoietic and endothelial cells (CD14, CD34, CD45) [4]. Our results were consistent with these criteria. BMSCs, ATSCs and DSCs shared expression of surface antigens; they were positive CD29, CD44, CD73, CD90, CD105 and CD166. They were negative for CD14, CD34 and CD45. Moreover, they did not express HLA-DR, which was also showed by other authors [12], [14]. It was shown that reduction of HLA-DR expression ensures the immunological tolerance of MSCs what increases their potential for clinical practice [15].

In addition we have demonstrated that BMSCs and ATSCs had potential to undergo chondrogenic differentiation comparable to chondrocytes. On the other hand this potential was significantly decreased in DSCs. This finding is in conflict with results obtained by Sanchez-Adams and Athanasiou [16]. But, they used micro-mass culture with combination with cocktail of growth factors (TGF- $\beta 1$, IGF-1, BMP-2) and other chemicals which increase economic burden of this approach. Moreover, they used only negative control so they did not have positive group for comparison.

In summary, we can emphasise that stem cells isolated from bone marrow, adipose tissue and dermis possess similar biological and morphological characteristics, but vary in potential for chondrogenic differentiation. Skin-derived stem cells have an inferior potential for chondrogenic differentiation. So this fact decreases their potential for cartilage tissue engineering. Hoverer, further studies focused on applying of appropriate exogenous factors have to be carried out to clarify this issue.

\section{REFERENCES}

[1] R. Strehl, T. Tallheden, E. Sjögren-Jansson, W. W. Minuth, and A. Lindahl, "Long-term maintenance of human articular cartilage in culture for biomaterial testing," Biomaterials, vol. 26, pp. 4540-4549, Aug. 2005.

[2] L. Danisovic, I. Varga, R. Zamborsky, and D. Böhmer, "The tissue engineering of articular cartilage: cells, scaffolds and stimulating factors," Exp. Biol. Med. (Maywood), vol. 237, pp. 10-17, Jan. 2012.

[3] R. M. Shanti, W. J. Li, L. J. Nesti, X. Wang, and R. S. Tuan, “Adult mesenchymal stem cells: biological properties, characteristics, and applications in maxillofacial surgery,"J. Oral. Maxillofac. Surg., vol. 65, pp. 1640-1647, Aug. 2007.

[4] M. Dominici, K. Le Blanc, I. Mueller, I. Slaper-Cortenbach, F. Marini, D. Krause, R. Deans, A. Keating, D. J. Prockop, and E. Horwitz, "Minimal criteria for defining multipotent mesenchymal stromal cells The International Society for Cellular Therapy position statement," Cytotherapy, vol. 8, pp. 315-317, Aug. 2006.

[5] M. Patterson, D. N. Chan, I. Ha, D. Case, Y. Cui, B. Van Handel, H. K. Mikkola, and W. E. Lowry, "Defining the nature of human pluripotent stem cell progeny," Cell Res., vol. 22, pp. 178-193, Jan. 2012.

[6] S. Kern, H. Eichler, J. Stoeve, H. Klüter, and K. Bieback, "Comparative analysis of mesenchymal stem cells from bone marrow, umbilical cord blood, or adipose tissue," Stem Cells, vol. 24, pp. 1294-1301, May 2006.

[7] X. F. Yang, X. He, J. He, L. H. Zhang, X. J. Su, Z. Y. Dong, Y. J. Xu, Y. $\mathrm{Li}$, and Y. L. Li, "High efficient isolation and systematic identification of human adipose-derived mesenchymal stem cells," J. Biomed. Sci., vol. 18, pp. 59, Aug. 2011

[8] J. G. Toma, I. A. McKenzie, D. Bagli, and F. D. Miller," Isolation and characterization of multipotent skin-derived precursors from human skin," Stem Cells., vol. 23, pp. 727-737, Jun-Jul 2005

[9] C. Alberti, "Tissue engineering: technological advances to improve its applications in reconstructive surgery," G. Chir., vol. 33, pp. 435-443, Nov. 2012.

[10] E. Arrigoni, S. Lopa, L. de Girolamo, D. Stanco, and A. T. Brini, "Isolation, characterization and osteogenic differentiation of adipose-derived stem cells: from small to large animal models," Cell Tissue Res., vol. 338, pp. 401-411, Dec. 2009.

[11] L. Danisovic, I. Varga, S. Polak, B. Bajcikova, M. Adamkov, and J. Vojtassak, "Biological and morphological characterization of in vitro expanded human muscle-derived stem cells," Tsitologiia, vol. 53, pp. 482-487, 2011.

[12] B. Delorme, and P. Charbord, "Culture and characterization of human bone marrow mesenchymal stem cells," Methods Mol Med., vol. 140, pp. 67-81, 2007.

[13] A. I. Caplan, "Mesenchymal stem cells," J. Orthop. Res., vol. 9, pp. 641-650, Sep. 1991.

[14] C. M. Mihu, D. Rus Ciucă, O. Soritău, S. Sușman, and D. Mihu, "Isolation and characterization of mesenchymal stem cells from the amniotic membrane," Rom. J. Morphol. Embryol., vol. 50, pp. 73-77, 2009.

[15] F. P. Barry, J. M. Murphy, K. English, and B. P. Mahon, "Immunogenicity of adult mesenchymal stem cells: lessons from the fetal allograft," Stem Cells Dev., vol. 14, pp. 252-265, Jun 2005.

[16] J. Sanchez-Adams and K. A. Athanasiou, "Dermis isolated adult stem cells for cartilage tissue engineering," Biomaterials, vol. 33, pp. 109-119, Jan. 2012.

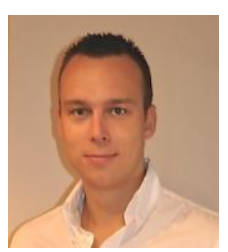

Martin Bohac was born in Bratislava, Slovakia, in March 1984. He received his M.D. in 2008 from Faculty of Medicine, Comenius University in Bratislava.

$\mathrm{He}$ is currently employed as a surgeon at Department of Plastic, Reconstructive and Aesthetic Surgery, Faculty of Medicine, Comenius University in Bratislava. His research is mainly focused on reconstructive surgery and stem cells. He published 12 scientific journal papers.

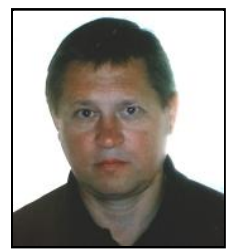

Stefan Polak was born in Bratislava, Slovakia, in January 1955. He received his M.D. in 1980 from Faculty of Medicine, Comenius University in Bratislava and his PhD. in Pathology from Comenius University in 1994.

He is currently employed as a head of Institute of Histology and Embryology, Faculty of Medicine, Comenius University in Bratislava. His research is mainly focused ultrastructural morphology and microcirculation of spleen. He published 2 scientific monographs, 4 university textbooks and more than 130 scientific journal and congress papers.

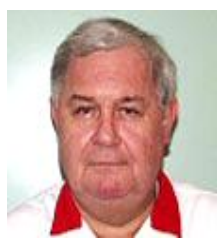

Jozef Fedeles was born in Bratislava, Slovakia, in February 1947. He received his M.D. in 1971 from Faculty of Medicine, Comenius University in Bratislava.

$\mathrm{He}$ is currently employed as a head of at Department of Plastic, Reconstructive and Aesthetic Surgery, Faculty of Medicine, Comenius University 
in Bratislava. His research is mainly focused on reconstructive and esthetic surgery of clefts. He published 2 university textbooks and more than 65 scientific journal and congress papers.

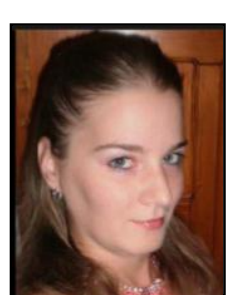

Zuzana Varchulova Novakova was born in Spiska Nova Ves, Slovakia, in July 1986. She received her MSc. in 2010 from Faculty of Science, Pavol Jozef Safarik University in Kosice.

She is currently employed as scientist at Institute of Medical Biology, Genetics and Clinical Genetics,

Faculty of Medicine, Comenius University in Bratislava. Her research is mainly focused on toxicity testing and nanomaterials. She published 12 scientific journal and congress papers.

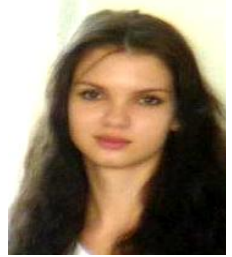

Jana Rusnakova was born in Banska Bystrica, Slovakia, in June 1987. She received her M.D. in 2012 from Faculty of Medicine, Comenius University in Bratislava.

Recently, she is a $\mathrm{PhD}$. student at Institute of Histology and Embryology, Faculty of Medicine, Comenius University in Bratislava. Her research is mainly focused on regenerative medicine and stem cells. She published 2 scientific papers.

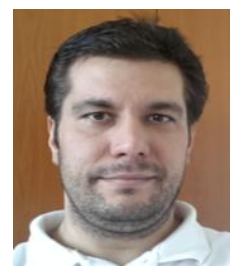

Lubos Danisovic was born in Bratislava, Slovakia, in November 1977. He received his MSc. in 2002 from Faculty of Natural Sciences, Comenius University in Bratislava and his $\mathrm{PhD}$. in General Biology from Comenius University in 2008.

$\mathrm{He}$ is currently employed as assistant professor at Medical Biology, Genetics and Clinical Genetics, Faculty of Medicine, Comenius University in Bratislava. His research is mainly focused on regenerative medicine and stem cells. He published 4 university textbooks and more than 70 scientific journal and congress papers 